\title{
La cultura del libro en el Tíbet*
}

\author{
Marta TORRES SANTO DOMINGO \\ (Biblioteca Histórica. Universidad Complutense de Madrid)
}

\section{Resumen}

El Tíbet ha desarrollado una cultura del libro muy rica y poco conocida en occidente. Su originalidad desde el punto de vista material va más allá de ser el producto resultante de las dos culturas dominantes en Asia, la india y la china. Y su inmenso potencial simbólico abarca valores sagrados, políticos, económicos o artísticos, que explican aspectos de una sociedad que ha desarrollado una cultura compleja y singular. La grave destrucción del patrimonio bibliográfico y documental tibetano en el pasado, se ha visto en los últimos tiempos superado por un mayor interés en la investigación y acciones de conservación y difusión de las colecciones existentes.

Palabras clave: Tíbet; Potbi; Libro; Imprenta; Budismo.

\section{Tibetan Book Culture}

\section{Abstract}

Tibet has developed a very rich book culture that is little known in the West. Its books' uniqueness from a material point of view goes beyond their being the product of the two dominant cultures in Asia: those of India and China. Their immense symbolic value is bound up with their sacred, political, economic and artistic importance, and this needs to be stressed because it helps to explain aspects of a society that has developed a complex and unique

\footnotetext{
${ }^{*}$ Este trabajo se presentó en la Jornada de Trabajo del Proyecto Sumptibus, «Quid est liber. Los valores del libro», que tuvo lugar el 27 de octubre 2017, en la Biblioteca Histórica «Marqués de Valdecilla» de la Universidad Complutense de Madrid.
} 
culture. The disastrous destruction of Tibetan books and documents in the past has recently been attenuated by a greater emphasis on research, conservation and spreading information about surviving collections.

Keywords: Tibet; Pothi; Books; Printing; Buddhism.

\section{Introducción}

En la cultura tibetana el libro tiene un inmenso potencial simbólico y, a través de él, se puede analizar la compleja estructura de una sociedad tan singular: su historia, su espiritualidad, el paso de la oralidad a la escritura, el desarrollo tecnológico y científico alcanzado, los modos de producción, los valores literarios, artísticos o estéticos, la organización sociopolítica, etc.

La excentricidad del tema, en el marco de los estudios del libro antiguo en España, debe entenderse como una aportación que se sale de nuestro eurocentrismo habitual para ocuparse de una cultura que está más allá de la «Galaxia Gutenberg», y que junto con otras culturas orientales (la china, la india, la japonesa, la coreana, etc...), han tenido una riquísima y fructífera historia del libro que debe ser conocida y valorada por los estudiosos del libro en España. ${ }^{1}$

Peter Burke, conocido especialista en historia de la cultura, incidía en un Congreso sobre La imprenta en el Tíbet como agente de cambio, celebrado en Cambridge en $2013,{ }^{2}$ en la necesidad de llevar a cabo una historia comparativa entre las imprentas europea y oriental que incluyera tanto las similitudes y funciones equivalentes como las diferencias, y tuviese en cuenta, además, la llamada historia cruzada, es decir la búsqueda de conexiones internacionales e intercontinentales. Él mismo confesaba que el estudio de la imprenta en China o en Japón le había ayudado a entender aspectos de lo que pasó en Europa, al

\footnotetext{
${ }^{1}$ Uno de los pocos estudiosos en España del libro antiguo oriental, en concreto el japonés, ha sido el profesor José Luis GONZALO SÁNCHEZ-MOLERO, Leyendo en Edo: breve guía sobre el libro antiguo japonés, Madrid, Consejo Superior de Investigaciones Científicas, 2013. Recientemente se ha publicado en la red, en español, una breve aproximación divulgativa al libro tibetano a cargo del bibliotecario argentino Edgardo CIVALLERO, Libros y bibliotecas en el Tíbet, distribuido como pre-print bajo licencia Creative Commons by-nc-nd 4.0, $<$ https://www.aacademica.org/edgardo.civallero/128.pdf> [Consulta 10-03-2018].

2 Printing as an Agent of Change in Tibet and Beyond, 28-30 november 2013, organised by the Mongolia and Inner Asia Studies Unit (MIASU), Cambridge. Las ponencias han sido publicadas en la obra, Tibetan Printig: Comparisons, Continuities and Change, edited by Hildegard DIEMBerg, Franz-Karl EHrHARD and Peter KorNiCKI, Leyden, Boston, Brill, 2016. Además de la versión impresa, esta obra está accesible libremente en la red, en Open access, en la dirección: <http://booksandjournals.brillonline.com/content/books/97890 04316256> [Consulta 10-03-2018].
}

Titivillus, ISSN 2387-0915, ISSN-e 2603-9966, 4 (2018), pp. 127-138 
revelarle caminos que no se habían tomado, pues la comparación nos hace conscientes de alternativas posibles y provoca la búsqueda de explicaciones. ${ }^{3}$

Hay que mencionar, como antecedente a este tema, una microexposición celebrada en el año 2014 en la Biblioteca Histórica de la Universidad Complutense de Madrid para dar a conocer al público en general el formato pothi, en la que se hizo un primer acercamiento al libro tibetano, exponiéndose algunos ejemplares impresos de la colección privada del profesor Gonzalo Sánchez-Molero, acompañados de otros libros de la Biblioteca Histórica y fotografías actuales de bibliotecas del Tíbet. ${ }^{4}$

Desde el punto de vista geográfico me voy a referir al Tíbet como una amplia área de influencia en la que, a lo largo de los siglos, se ha desarrollado la cultura tibetana. Es un área que recorre la meseta tibetana y el Himalaya en ambas vertientes, se instala en sus valles y montañas, desde las estribaciones occidentales en la región de Ladakh (India), hasta la zona oriental de Sikkim (India), o Bután. En la vertiente norte del Himalaya y ya en el altiplano, la forma de vida tibetana se extiende hacia el norte, el este y el oeste por grandes regiones de la China actual. Es, por tanto, una cultura que se ha desarrollado, con variedades locales, en diferentes países.

\section{La materialidad del libro tibetano}

La aparición de la cultura libraria en el Tíbet está estrechamente asociada a la difusión del budismo dado que, antes de su llegada en el siglo VII, el libro no existía. Además, el origen religioso del libro es el que justifica el formato adoptado y otras características materiales.

Mientras en Europa y occidente el formato librario habitual desde la Edad Media es el llamado codex, en Asia millones y millones de personas han leído, a lo largo de los siglos hasta tiempos recientes, en otros formatos,

\footnotetext{
3 Peter Burke, «Three Print Revolutions», en Tibetan Printig: Comparisons, Continuities and Change, pp. 13-20.

4 José Luis Gonzalo Sánchez-Molero y Marta Torres SAnto Domingo, «Microexposición: Los otros libros, el libro pothi oriental», en Folio Complutense, Blog de la Biblioteca Histórica de la UCM, 28 de marzo 2014, <http://biblioteca.ucm.es/blogs/ Foliocomplutense/8738.php> [Consulta 10-03-2018]. Acompañando la exposición se publicaron diferentes colaboraciones sobre el tema: José Luis GONZALO SÁNCHEZMOLERO, «La historia milenaria del pothi», en Folio Complutense, 9 de abril 2015, $<$ http://biblioteca.ucm.es/blogs/Foliocomplutense/8753.php> [Consultado 10-03-2018]; Marta Torres SANTO Domingo, «Bibliotecas, libros e imprentas en el Tíbet», en Folio Complutense, 13 de septiembre 2013, <http://biblioteca.ucm.es/blogs/Foliocomplutense /8005.php> [Consultado 10-03-2018]; Marta TORRES SANTO DOMINGO, «Johann Grueber y la imagen del Potala», en Folio Complutense, 30 de abril 2014, <http://biblioteca.ucm. es/blogs/Foliocomplutense/8754.php> [Consultado 10-03-2018]; Marta AguiLAR Moreno, «Derge, el cielo del libro tibetano», en Folio Complutense, 26 mayo 2014, <http: //biblioteca.ucm.es/BUCM/blogs/Foliocomplutense/8915.php> [Consultado 10-032018].
}

Titivillus, ISSN 2387-0915, ISSN-e 2603-9966, 4 (2018), pp. 127-138 
fundamentalmente el pothi y el rollo. El formato pothi, tradicional en la India y todo el subcontinente asiático, está construido a partir de hojas de forma rectangular o apaisada, apiladas unas sobre otras, cosidas o no y protegidas por tela o dos tablas de madera. El formato rollo es característico de China y puede adoptar diferentes soportes, en tiras de bambú, seda o papel.

El formato que se adoptó en el Tíbet y en todo el Himalaya, a partir del siglo VII, fue el formato pothi, quizás porque el budismo indio fue el que se impuso en el Tíbet, frente al chino. ${ }^{5}$ El formato pothi estaba asociado en la India con el soporte de la hoja de palma o de bambú, plantas inexistentes en el Himalaya, por lo que, muy pronto, el libro tibetano pothi fue producido a partir del papel, cuya fabricación se difundió desde China durante los siglos VII y VIII a través de las vías de influencia de la Ruta de la Seda.

Hay que indicar, sin embargo, que el papel usado para los libros tibetanos es de unas características muy diferentes a las de China pues en el Tíbet, donde hay muy poca vegetación en el altiplano, se usaron fibras de unos arbustos que sólo crecen en el bajo Himalaya y el papel resultante es más grueso, fuerte y basto que el chino. El arbusto más frecuente para este menester pertenece a la familia de las timeleáceas (Daphne, Edgeworthia, otras), tiene propiedades contra insectos y crece abundantemente en las zonas más bajas del Himalaya, como en Nepal y Bután, lugares tradicionales de producción de papel para el libro tibetano. Este papel permitía la fabricación de hojas de mayor tamaño por lo que otra característica de los libros pothi tibetanos es que son bastante más grandes que los indios. ${ }^{6}$

El estudio de la materialidad de libro en el Tíbet, además del papel, debe incluir otros aspectos como las tintas y las recetas con las que se fabricaban; los cálamos, que son el instrumento escriptorio más habitual, heredado de la India, en vez del pincel, como se escribía en China; los colores utilizados que dependían de los pigmentos disponibles y de la teoría tibetana del color (basados en los cinco principales: blanco, negro, rojo, azul y amarillo); las sedas y cubiertas de protección, etc.

Al principio, como en Europa, los libros eran copiados a mano, pero a partir del siglo XIII, comenzó a utilizarse la imprenta, no de tipos móviles, como la de Gutenberg, sino a partir de planchas xilográficas grabadas. La imprenta se difundió a muchos lugares desde finales del siglo XIV y su edad de oro se sitúa en el siglo XVIII.

Desde el punto de vista material, el libro tibetano es, por tanto, el producto resultante del contexto religioso en el que nace, y de la adaptación a su medio geográfico, político y medioambiental, del mundo librario de las dos

\footnotetext{
${ }^{5}$ En un famoso suceso conocido como el Gran Debate de Samya (792-794)

${ }^{6}$ Recomendable para entender el libro tibetano, desde el punto de vista material, es la obra: Agnieszka HeLman-WaZny, The archaeology of Tibetan Books, Leiden, Brill, 2014; Además, da una información muy completa: Mark ELLIOT, Hildegard DiEMBERGER \& Michela Clemente, Buddha's Word: The Life of Books in Tíbet and Beyond, Museum of Archaeology and Antropology, University of Cambridge, 2014.
} 
culturas dominantes en Asia, la india y la china, con un formato que viene del sur, el pothi, y un soporte, el papel, que viene del norte. Y a partir de este formato se desarrolló una literatura, en gran parte religiosa, pero también con obras maestras de la épica, teatro, poesía, biografía, etc.

\section{El valor sagrado}

En el libro tibetano prima el valor religioso por encima de todo, por ser la encarnación de la voz de Buda. Pero es también el principal instrumento de educación, fuente de tradición y autoridad, herramienta política de las élites para su fines propagandísticos, producto económico, forma de pagos de impuestos, objeto artesanal con características estéticas y artísticas que lo equiparan a la pintura o a la escultura e, incluso, material peligroso en la represión política. Hay muchos aspectos en la cultura libraria del Tíbet que podemos reconocer en la cultura europea. Se comenzará este análisis por su consideración sagrada.

Un testimonio de valor antropológico se encuentra en el relato del famoso viajero Michel Peissel, uno de los primeros que exploró el valle del Mustang (Nepal) en los años sesenta del siglo pasado. Así explicaba el valor del libro:

... Tras haber tomado el té, el lama nos acompañó a una habitación contigua, donde había un gran número de libros. Como todos los volúmenes tibetanos, se componían de un número de hojas largas, rectangulares, envueltas en seda y sujetas entre tablas. Cada vez que solicitábamos mirar un libro, el lama se lo colocaba sobre la cabeza en señal de reverencia, y luego se lo ponía sobre la de Tashi; finalmente nos lo entregaba. Todo tibetano ejecuta este pequeño ritual cuando va a leer un libro. En el Tíbet se considera a los libros mucho más que como simples textos. Se les venera como algo sagrado en si mismo y poseedores de propiedades que se extienden más allá de su estricto significado. Se los considera más santos que las propias estatuas e imágenes, por lo cual no se les coloca nunca debajo de una de estas. Son tratados con el mayor respeto. Casi todos los monjes del Himalaya saben leer, pero pocos son los que entienden la complicada gramática y la terminología de los textos religiosos tibetanos. Para estos monjes, no demasiado cultos, el sólo hecho de volver las páginas de un libro religioso o murmurar sin comprenderlas las sílabas escritas en él, resulta suficiente para adquirir mérito... ${ }^{7}$

Estos rituales no son exclusivos de la cultura tibetana. En el cristianismo la Biblia es venerada en el oficio sagrado y, en la liturgia de la palabra el sacerdote eleva el libro antes de la lectura. Igualmente, los libros sagrados del

${ }^{7}$ Michel PeIsSEL, Mustang, reino probibido del Himalaya, Barcelona, Juventud, 1969, pp. 192193. 
islam o del judaísmo, el Corán y la Torah, son considerados sagrados y los ejemplares más valiosos son tocados sólo por personas autorizadas. En los templos de la religión sij, el libro contenedor de toda su doctrina, Granth Sabib, es adorado en vistosas ceremonias, tratado como una persona viva, y en sus rituales le levantan, le acuestan, le llevan en procesión o le abanican. Son ejemplos paradigmáticos del valor sagrado del Libro y de cómo la sacralidad va del todo, Dios, a su representación, el Libro que contiene los sagrados textos.

El libro tibetano comparte esta significación con otras culturas y es objeto de veneración por los textos que contiene pero también como objeto en sí mismo, formando parte de las prácticas devocionales. El libro se lleva en procesión, al libro se le adora, se le besa, se pasa por debajo de ellos. Leer, escribir, copiar, encargar, imprimir, o poseer libros supone adquirir mérito. Los textos también proporcionan protección y, así, hay un modelo de relicarios (en tibetano gau o ga'u) que, en forma de pequeñas cajas o contenedores que llevan breves textos escritos enrollados o doblados en su interior, se cuelgan como amuletos o se transportan en altares portátiles. ${ }^{8}$

Los libros más extraordinarios se guardan en los lugares más sagrados, los propios templos y capillas. Destacan los grandes estantes de madera de las salas principales de oración, a izquierda y derecha de las estatuas más veneradas, en los que se almacenan los 108 volúmenes de las enseñanzas orales de Buda, el Kangyur, o la colección de los 224 volúmenes de los comentarios a las escrituras budistas, el Tengyur. Y no sólo se almacenan los textos básicos, sino auténticas bibliotecas de libros religiosos y obras filosóficas, médicas, astronómicas, literarias, etc. Todavía hoy se conservan algunas riquísimas bibliotecas a las que, como en el monasterio de Palkhor, fundado en el siglo XV en la ciudad de Gyantse, se accede por la sala de oraciones.

Los libros religiosos tibetanos tienen, además, un extraordinario valor de rareza motivado por la historia misma del budismo. A partir del siglo VII las escrituras budistas indias escritas en sanscrito empiezan a ser traducidas al tibetano. En poco tiempo se calcula que se habían traducido más de 4.500 obras individuales, muchas de las cuales se perdieron en las copias originales en sánscrito cuando el budismo fue desapareciendo de la India. Por esta razón, los tibetanos se convirtieron en los únicos guardianes del corpus completo original de la religión budista que, junto con las obras creadas por los propios maestros tibetanos llegó a ser, probablemente, la colección más rica de literatura religiosa en el mundo. El mantenimiento de estos textos fue una prioridad. ${ }^{9}$

\footnotetext{
8 «The protective power of words», en Mark ELLIOT, Hildegard DiEMBERGER \& Michela Clemente, Buddha's Word, pp. 70-72.

9 Rebecca J. KNUTH, «China's Destruction of the Libraries of Tibet», en Lost libraries: the destruction of Great Book collections since antiquity, edited by James RAVEN, Palgrave Macmillan, 2004.
}

Titivillus, ISSN 2387-0915, ISSN-e 2603-9966, 4 (2018), pp. 127-138 


\section{El valor político y económico}

Al valor sagrado del libro tibetano se suma un valor político muy relevante, pues el budismo fue inseparable, en muchos momentos, de los intereses de los Estados asiáticos, tal como aconteció tantas veces en Europa con el cristianismo. El budismo y los textos sagrados que contenían la doctrina fueron utilizados como herramienta de la vida política, bien por oposición a otras religiones (confucionismo, taoismo, bonpo, etc.), bien como símbolo de la construcción de la identidad dinástica o nacional en periodos determinados. El patronazgo de las artes del libro por parte de los gobernantes iba, por tanto, más allá de la adquisición de mérito individual y llegó a tener un importante significado de búsqueda de legitimidad política y acrecentamiento de poder.

Desde la época de la dinastía Yuan (1279-1368), los khanes mongoles utilizaron el budismo para someter al Tíbet bajo su soberanía, estableciendo un estrecho vínculo con el lamaísmo tibetano que ejerció en esta época el liderazgo espiritual del pueblo mongol, a través de la figura de Sakya Pandita. La propagación del budismo necesitaba de instrumentos, no sólo monjes sino textos sagrados, y su multiplicación fue propiciada por la imprenta, ya conocida en China.

En este punto es necesario mencionar algunos ejemplos de patronazgo de la imprenta que están en relación, además, con el papel de la mujer en la sociedad de su época, con un paralelismo con lo que sucedía en la Europa de los mismos siglos (Baja Edad Media y Edad Moderna). Tanto en Europa como en Oriente encontramos un pequeño número de mujeres de las élites, que sobresalen del papel subordinado que juegan en la sociedad respecto a los hombres, y que en el libro y en la imprenta encuentran un instrumento con el que actuar como promotoras de nuevas ideas, como difusoras de una nueva espiritualidad o como mediadoras y embajadoras en el intrincado mundo de las alianzas políticas y matrimoniales.

Se trata de una saga de mujeres poderosas que utilizaron la imprenta y la difusión del libro impreso para sus objetivos político-religiosos y que, en la actualidad, se las está empezando a dar a conocer a partir del estudio, fundamentalmente, de los colofones escritos al final de los textos y de las biografías de mujeres celebres. Porque, algo que comparten estas mujeres tibetanas con sus congéneres orientales e incluso europeas, es la desaparición de sus figuras en el velo de lo innombrado; es decir, su protagonismo en la historia ha sido ignorado hasta fechas muy recientes que nuevos estudios están sacando a la luz. Las pioneras serían la Emperatriz china Wu Zetian (siglos VII-VIII) la «mujer que inventó la imprenta» según Barret, la emperatriz japonesa Shotoku (siglo VIII) y, el caso que nos ocupa, las emperatrices mongolas de la corte de Yuan (siglo XIII). ${ }^{10}$

10 T. H. BARRET, The woman who discovered printing, New Haven \& London, Yale University Press, 2008; Peter KORNICKI, «Empress Shotoku as a Sponsor of Printing», en Tibetan 
Siguiendo esta estela, en el Tíbet encontramos en los siglos posteriores mujeres con un papel muy importante en la protección de la imprenta la cual, a partir de finales del siglo XIV, con la caída de la dinastía mongol Yunan, experimentó una gran difusión. Una de las mujeres más importantes fue Chokyi Dronma (1422-1455), hija del rey de Gungthang, en el suroeste del Tíbet, que abandonó la corte para dedicarse a la vida religiosa, a la educación de las mujeres y a la edición de textos de sus maestros (Bodong Panchen y Thang Tong Gyalpo) a través de la incipiente imprenta de bloques grabados, que difundió notablemente pues fue muy consciente del poder ritual de las escrituras. ${ }^{11}$ La imprenta de Gungthang fue una de las más importantes durante los siglos XV, XVI y XVII y de ella salieron las ediciones príncipe de algunos textos que contribuyeron a crear una identidad nacional del pueblo tibetano. ${ }^{12}$

En paralelo a la importancia política del libro en el Tíbet, es notoria su relevancia como producto económico y símbolo de la riqueza de sus productores, donantes o coleccionistas. Hay que imaginar los cuantiosos excedentes de riqueza necesarios para poder dedicarlos a la fabricación masiva de papel y tintas, el establecimiento de escriptorium e imprentas con copistas, calígrafos, iluminadores, grabadores, entalladores de madera, impresores, etc.

El arte de la imprenta estaba asociado a los monasterios y no había monasterio por pequeño que fuere, que no tuviese su pequeña imprenta. En el caso de los monasterios grandes poseer una imprenta importante y bien surtida de planchas de madera xilográfica con los corpus más relevantes incrementaba su estatus y les permitía satisfacer las necesidades de su región de influencia mediante la realización de impresiones bajo demanda.

Una de las imprentas históricas más famosas y que ha llegado hasta nuestros días es la del monasterio de Derge, cuya edad de oro tuvo lugar en el siglo XVIII. Para hacerse una idea de lo masivo de su producción veamos un

Printig: Comparisons, Continuities and Change, pp. 45-50; Kawa SHERAB SANGPO, «Mongolian Female Rulers as Patrons of Tibetan Printing at the Yuan Court: Some Preliminary Observations on Recently Discovered Materials», en Tibetan Printig: Comparisons, Continuities and Change, pp. 38-44.

11 Murió a la edad de 33 años después de haber sido reconocida como reencarnación de Dorje Phagmo (emanación de Vajravarabi, encarnación de Dola (Tara), deidad tántrica femenina, consorte de Chenrezi Avalokitesvara) e inició una línea dinástica de rencarnación de mujeres que es la tercera jerarquía en importancia en el budismo tibetano, después del Dalai Lama y del Panchen Lama. Tiene su sede en el monasterio de Samding. Hildegard Diemberger, «Tibetan Women as Patrons of Printing and Innovation», en Tibetan Printig: Comparisons, Continuities and Change, pp. 267-308. Hildegard Diemberger, When a Woman becomes a Religious Dinasty: The Samding Dorje Phagmo of Tibet, New York, Columbia University Press, 2007.

${ }^{12}$ Un ejemplo es la obra conocida como Mani bka' 'bum, una colección de relatos míticohistóricos, rituales y doctrinales atribuidos al primer rey del Tíbet, Songten Gampo (siglo VII), que incluye biografías del propio rey y del Buda de la Compasión Avalokitesvara (en tibetano Chenrezı), del cual el Dalai Lama es emanación. Ver, Michela Clemente, «The Mani bka' 'bum», en Mark Elliot, Hildegard Diemberger \& Michela Clemente, Buddha's Word, pp. 88-89.

Titivillus, ISSN 2387-0915, ISSN-e 2603-9966, 4 (2018), pp. 127-138 
ejemplo. El Kanguyr de Derge, una vez que se terminaron de abrir todas las planchas xilográficas nuevas, en el año 1733, ocupaba 33.000 planchas xilográficas. Durante los años siguientes se llegaron a imprimir 125 colecciones al año, es decir, imprimir una copia completa del Kangyur llevaba tres días de trabajo, unos 11.000 folios impresos al día. Si tenemos en cuenta que, además del Kangyur, se imprimían otros textos (el Tengyur y muchos más), la imprenta de Derge debía tener una enorme concentración de recursos económicos y humanos. La unidad de medida para el pago era en barriles (o fanegas de cebada) y el coste total de pagar por un juego completo del Tengyur a los editores, iluminadores, grabadores, escribas, xilógrafos, fabricantes de papel, y materiales ascendía, a mediados del siglo XVIII, a unos 250.000 barriles de cebada. ${ }^{13}$ Hoy en día, han sobrevivido más de 270.000 planchas en la imprenta de Derge, que se ha convertido en un museo vivo. ${ }^{14}$

\section{El valor artístico}

Como en todas las culturas, también en la tibetana algunos libros singulares fueron caracterizados por unos elementos formales que les distinguían, bien por su especial sacralidad, bien para subrayar el prestigio de su poseedor, o bien para dar relevancia al donante que patrocinó su edición. Estos elementos formales se caracterizan por el empleo de lujosos materiales (maderas nobles, oro, plata y joyas) y una elevada calidad artística, que nos hablan sobre la percepción estética de la sociedad tibetana y de las diversas corrientes de influencias que transitaban por el Himalaya, desde el arte de Cachemira a otros estilos de Asia Central, la India, Nepal, o China.

Dentro del arte librario del Tíbet destacan dos aspectos en los que sobresale con un papel brillante en la historia del arte, los libros negros crisográficos y las encuadernaciones.

Los libros negros crisográficos (en tibetano thingshog,) son manuscritos cuyo soporte papel está teñido en un color azul oscuro o negro, y escrito con tintas de oro o plata con caligrafías exquisitas. ${ }^{15}$. Existen manuscritos similares para obras muy singulares en otras culturas, especialmente en la islámica, Blue Coran, pero en el Tíbet fueron muy frecuentes. ${ }^{16}$ Estos ejemplares de especial

${ }^{13}$ Kurtus R. SCHAEFFER, The culture of book in Tibet, New York, Columbia University Press, 2009, pp. 92, 159 y ss.

14 Marta Aguilar Moreno, «Derge, el cielo del libro tibetano».

15 James CANARY aporta el método de fabricar este soporte azul-negro: sobre un papel fuerte y de buena calidad, con varias capas, se extiende una pasta elaborada con sesos frescos de yak, oveja o cabra, pegamento de origen animal (fabricado con huesos, tendones y piel del yak), y hollín que luego se deja secar y finalmente se pule. Véase: «Thingshog (mthing shog): Luxury illuminated manuscripts on blue-black papers en Mark ELLIOT, Hildegard Diemberger \& Michela Clemente, Buddha's Word, pp. 109-111.

16 De hecho, la especialista en manuscritos islámicos, Dagmar A. RIEDEL, aventura que el Corán azul naciera de la influencia de los manuscritos budistas, dada la estrecha 
calidad estaban decorados con una gran variedad de iluminaciones como miniaturas, iniciales, bordes ornamentados, o círculos, especialmente en la primera página. El famoso maestro y erudito budista Pakpa Lodro Gyeltsen, que llegó a ser preceptor imperial del emperador mongol Kublai Khan, escribió unos versos dedicados a la belleza de estos libros thingshog:

Papel azul-negro, con el resplandor de un gran zafiro, embellecido con cadenas de letras doradas, es como si su luz eclipsara, el brillo del sol

O, Papel azul-negro, con el resplandor del pájaro tingka, es como el color del cielo azul claro.

Las letras de oro organizadas, como las estrellas y los planetas dispuestos en una línea... ${ }^{17}$

Un ejemplo excepcional es el manuscrito que contiene la Sutra del Kangyur, La grande, noble y purificadora liberación de todos los pecados a través de Buda, de la Biblioteca Estatal de Baviera (Sig. BSB: Cod. Tibet. 922); aunque no es muy antiguo, ya que está copiado en el siglo XIX, está disponible en la Biblioteca Digital Mundial de la UNESCO. ${ }^{18}$ En otro magnífico ejemplo de la Sutra de la Gran Liberación, depositado en la National Library of Medicina de EEUU, cada hoja del papel negro tiene siete líneas, cada una de ellas escrita con una tinta diferente, hecha de sustancias preciosas conocidas como las «Siete joyas»: oro, plata, cobre, coral, lapislazuli, malaquita y madre perla. ${ }^{19}$

El desarrollo artístico del libro tibetano alcanzó su más alta perfección en las encuadernaciones, en realidad cubiertas formadas por tablas de madera entre las que se protegían las hojas de papel de los textos (en tibetano legshing o glegs shing). En los ejemplos más elaborados, la parte externa de la cubierta está labrada con bajorrelieves de figuras o filigranas geométricas, pintadas y doradas, decoraciones de oro y plata o incrustaciones de piedras semipreciosas como turquesas, coral, ámbar o marfil. Aunque más raras, se pueden encontrar cubiertas completas de marfil, plata y oro. Previamente, las hojas se

convivencia de culturas en Asia Central. Véase la nota de blog «The anxiety of Influence: Framing the Blue Quran», en Islamic Books: A Research Blog about Manuscripts, Printed Books, and Ephemera in Arabic Script, 10 mayo 2013: <https://researchblogs.cul.columbia.edu /islamicbooks/tag/chrysography/> [Consultado 10-03-2018].

17 Versión española de la autora, tomada de la versión inglesa que aparece en: Kurtis R. SCAEFFER, The culture of the book in Tibet..., pp. 132. «Blue-black paper, with the radiance of a great sapphire/Embellished with strings of Golden letters-/It is as if its light outshines/The brightness of the sun.//Or else, the blue-black paper, with the radiance of the tingka bird,/is like the color of the clear blue sky./The Golden letters arrayed/are like the stars and planets arranged in a line...»

$18<$ https://www.wdl.org/es/item/8943/>

${ }_{19}$ Hidden Treasure of National Library of Medicine, New York, Blast Books, 2012, pp. 76-77.

Titivillus, ISSN 2387-0915, ISSN-e 2603-9966, 4 (2018), pp. 127-138 
envuelven en finas telas de seda. Con frecuencia, estas cubiertas han sido separadas de los textos que protegían y tratados como objetos de arte individuales. Esta descontextualización puede dificultar su verdadera interpretación, pues en muchos casos las imágenes decorativas de las cubiertas están en estrecha relación con los textos para las que fueron creadas. Las cubiertas de los libros se consideran uno de los elementos más originales de la materialidad de la cultura libraria del Tíbet y, en la actualidad, se está prestando una especial atención por parte de los investigadores. ${ }^{20}$

El libro ha sido, además, elemento recurrente en las representaciones artísticas, asociado, como en Occidente, al conocimiento, a la sabiduría suprema, a lo más sagrado. Y tanto en pinturas como en esculturas aparecen personajes cuyo atributo es un libro entre las manos. Dentro de la iconografía del complejo panteón budista, un ejemplo destacado en este sentido son los llamados arhats o santos inmortales, un conjunto de dieciséis hombres que, según la tradición, fueron discípulos directos del Buda histórico, es decir, que vivieron entre los siglos VI y V antes de Cristo. Buda les envió por todo el mundo a predicar sus enseñanzas y como los apóstoles en el cristianismo, son varios los que llevan como atributo un libro entre las manos.

En el Tíbet apareció junto a los arbats un personaje netamente tibetano. Se llama Dharmata, y es el protector y el bibliotecario de los arbats, el que les lleva los libros, se los cuida, y los tiene a su disposición. Iconográficamente es la trasposición de un personaje chino muy conocido, el monje budista Xuanzang (siglo VII) que en un memorable viaje llevó de la India a China innumerables textos budistas que luego tradujo o mandó traducir. Como a Xuanzang, a Dharmata se le representa siempre cargado a la espalda con una caja llena de libros y, en ocasiones, acompañado de un tigre para hacer frente a los peligros del camino. Gracias a él los hombres santos viajan seguros por el camino de la sabiduría y la iluminación.

\section{Destrucción, preservación e investigación del libro en el Tíbet}

Hay un hecho que ejemplifica muy bien la enorme carga simbólica que tiene el libro en el Tíbet por su valor religioso, político y educativo. Me refiero a la terrible destrucción del patrimonio bibliográfico y documental tibetano llevado a cabo por el gobierno chino desde la ocupación militar del Tíbet en 1950, año en el que comenzó la represión de todo lo que tuviese que ver con la identidad cultural tibetana. Este «etnocidio» fue creciendo con las revueltas de 1959 que propiciaron la salida del Dalai Lama y su exilio desde entonces en la India. Pero, sobre todo, se precipitó a partir de 1966, en la época de la llamada «Revolución Cultural», terrible lucha de poder enmascarada tras una campaña de masas en las que éstas eran dirigidas a acabar con la traición de los

\footnotetext{
${ }^{20}$ Un ejemplo es la reciente celebración de una de las primeras exposiciones de este tipo de cubiertas, en Estados Unidos: Kathryn H. SELIG BROWN, Protecting Wisdom: Tibetan Book Covers from the MacLean Collection, Chicago, Munich, MacLean Collection, Prestel, 2012.
} 
que, según Mao y su banda, se agarraban a lo viejo, a la ideología burguesa reaccionaria. La consecuencia demoledora fue la liquidación de gran parte de la clase intelectual china y una destrucción masiva de obras de arte y libros. Se ha llegado a calcular que ha desaparecido el $60 \%$ de la literatura tibetana existente y el $85 \%$ de los archivos y documentos que se guardaban en miles de monasterios desde el siglo VIII.

Símbolo de ese horror es la quema de libros en el patio central del principal templo de Lhasa, el Johkang, en el que el 25 de agosto de 1966 lanzaron a la hoguera los libros y documentos que guardaba. Para ayudar a la desacralización y contribuir a la humillación del pueblo tibetano, los libros que no se quemaron se usaron para envolver mercancías en las tiendas chinas, para hacer zapatos, las encuadernaciones de madera para hacer suelos, sillas, instrumentos e incluso, el papel, se obligó a utilizarlo como papel higiénico. Además, la antigua imprenta del Potala fue destrozada, y a lo largo de todo el Tíbet, imprentas y textos fueron rotos, incendiados, desacralizados y tirados a la basura. En otros casos, el expolio de libros y objetos tibetanos terminó alimentando las casas de anticuarios de Hong Kong y Tokio y, hoy en día, están en manos de colecciones públicas o privadas. ${ }^{21}$

Pero quiero terminar aportando un poso de optimismo y esperanza sobre la preservación y valoración del libro en el Tíbet. Por un lado, es una realidad el crecimiento relativo de estudios sobre el libro tibetano. Son muchos los especialistas que han centrado sus investigaciones en este campo, en la creencia de que la historia del libro no estaría completa sin un capítulo tan relevante. Gracias a estos estudios, se puede llegar al conocimiento de textos muy importantes para conocer mejor no sólo la cultura tibetana sino la memoria de la humanidad. En este sentido, hay que volver a subrayar la riqueza de la literatura tibetana. Aunque una gran mayoría de los textos conservados son de naturaleza religiosa (textos canónicos, filosofía, obras de meditación y rituales), la cultura tibetana ha cultivado otros géneros como la historia, mitología, biografías, cuentos, leyendas, poesía, épica, teatro, gramática, leyes, ciencias, astronomía o medicina.

Por otro lado, es cada vez mayor el cuidado y preservación que se está haciendo del libro tibetano desde muchas instituciones. Museos y bibliotecas en occidente y en Asia, incluyendo China, empiezan a estudiar y a poner en valor sus colecciones, con catálogos, exposiciones y publicaciones. Además, el exilio tibetano a través de la Library of Tibetan Works and Archives, está recopilando miles y miles de manuscritos, libros y documentos antiguos, para preservarlos y con ellos proteger su identidad cultural.

\footnotetext{
${ }^{21}$ Rebecca J. KNUTH, «China's Destruction of the Libraries of Tibet», en Lost libraries: the destruction of Great Book collections since antiquity, pp. 247-260.
} 